\title{
Short communication: Hepatic progesterone-metabolizing enzymes cytochrome P450 2C and 3A in lactating cows during thermoneutral and heat stress conditions ${ }^{1}$
}

\author{
V. L. McCracken, ${ }^{*}$ G. Xie, ${ }^{*}$ S. E. Deaver, ${ }^{*}$ L. H. Baumgard,† R. P. Rhoads, ${ }^{*}$ and M. L. Rhoads ${ }^{* 2}$ \\ *Department of Animal and Poultry Sciences, Virginia Polytechnic Institute and State University, Blacksburg 24061 \\ †Department of Animal Science, lowa State University, Ames 50011
}

\section{ABSTRACT}

Two experiments were performed to determine the effects of heat stress (HS) and insulin on hepatic mRNA abundance of enzymes responsible for metabolizing progesterone [cytochrome P450 2C and 3A (CYP2C and CYP3A)]. To distinguish the direct effects of HS from decreased dry matter intake, cohorts were pair fed $(\mathrm{PF})$ in thermoneutral conditions to match the intake of the HS cows during both experiments. In the first experiment, multiparous late-lactation Holstein cows (n $=12,305 \pm 33 \mathrm{~d}$ in milk) housed in climate-controlled chambers were subjected to 2 experimental periods: (1) thermoneutral (TN) conditions $\left(18^{\circ} \mathrm{C}, 20 \%\right.$ humidity) with ad libitum intake (TN and well fed) for $9 \mathrm{~d}$; and (2) either HS conditions (cyclical temperature $31-40^{\circ} \mathrm{C}$, $20 \%$ humidity) fed for ad libitum intake $(\mathrm{n}=6)$, or $\mathrm{TN}$ conditions and PF to match the HS animal ( $\mathrm{n}=$ 6 ) for $9 \mathrm{~d}$. To evaluate hepatic gene expression during experiment 1 , biopsies were obtained at the end of each period. In the second experiment, multiparous mid-lactation Holstein cows $(\mathrm{n}=12,136 \pm 8$ DIM) were housed and fed in conditions similar to those described for the first experiment. Liver biopsies were obtained immediately before and after an insulin tolerance test administered on d 6 of each period. No effects of exogenous insulin were observed on any of the tested variables, nor were there interactions between environment (TN/HS or well fed/PF) and insulin administration. Heat stress decreased hepatic CYP2C expression during both experiments. The relative abundance of CYP3A was not affected by environmental conditions in the late-lactation cows (first experiment), but was reduced by HS in the mid-lactation cows (second experiment). Interestingly, during experiment 2, hepatic

\footnotetext{
Received September 6, 2014.

Accepted January 25, 2015.

${ }^{1}$ This work was supported by National Research Initiative Competitive Grant no. 2008-35206-18817 and Agriculture and Food Research Initiative Competitive Grant no. 2010-65206-20644 from the USDA National Institute of Food and Agriculture.

${ }^{2}$ Corresponding author: rhoadsm@vt.edu
}

CYP3A expression also decreased during PF. These results suggest that HS reduces the capacity of the liver to metabolize progesterone through distinct effects on CYP2C and CYP3A, and that the effects appear to vary based upon stage of lactation. Ultimately, HS may affect reproductive outcomes by reducing the abundance of the enzymes responsible for the breakdown of progesterone. This reduction could serve as a beneficial adaptation for rescuing early embryos or may be detrimental, as it affects feedback mechanisms necessary for proper cyclicity.

Key words: progesterone, heat stress, insulin, fertility

\section{Short Communication}

Environmental factors such as heat stress (HS) greatly affect the endocrine and metabolic status of dairy cattle while severely reducing their reproductive performance (Rhoads et al., 2009; 2010). Reproductive success is dependent upon appropriate circulating concentrations of hormones such as progesterone, as it is critical to reproductive events ranging from follicular development to the maintenance of pregnancy (Wiltbank et al., 2011). Whereas many have shown that HS affects circulating progesterone concentrations in cattle, results have been highly variable (Abilay et al., 1975; Roman-Ponce et al., 1981; Rosenberg et al., 1982; Wolfenson et al., 1988). These apparent discrepancies are likely due to study-specific variation in the factors that determine circulating concentrations, including progesterone production (luteal and possibly adrenal), hepatic blood flow or metabolism, hemodilution, and hemoconcentration (Trout et al., 1998)

Progesterone metabolism by the liver is influenced by many factors, one of which is insulin. This is of particular interest because during HS, cattle (and other species) typically have elevated circulating insulin concentrations (O'Brien et al., 2010; Wheelock et al., 2010); especially when compared with thermoneutral animals on a similar plane of nutrition (Baumgard and Rhoads, 2013). Progesterone is metabolized in the liver in 2 phases: it is first hydroxylated by enzymes 
cytochrome P4502C and 3A (CYP2C and CYP3A, respectively), then conjugated with glucuronic acid to create the inactive hydroxyprogesterone-glucuronide metabolite (Lemley and Wilson, 2010). Hepatocytes cultured with insulin have reduced rates of progesterone metabolism (Smith et al., 2006), and when insulin is intravenously infused into lactating dairy cattle, hepatic expression of both CYP2C and 3A decrease (Lemley et al., 2008). Similarly, when glucose is infused intravenously into nonlactating cows, serum insulin concentrations increase whereas hepatic expression of both enzymes decreases (Vieira et al., 2013).

The mechanism(s) responsible for insulin-mediated regulation of hepatic CYP2C and CYP3A expression is not fully understood. Peroxisomal proliferator activated receptor- $\gamma$ coactivator $1 \alpha(\mathbf{P G C 1} \boldsymbol{\alpha})$ is potentially involved, as it has been identified as a transcriptional regulator for the cytochrome P450 (CYP) superfamily (Martínez-Jiménez et al., 2006). Elevated insulin concentrations have been shown to decrease human hepatocyte PGC1 $\alpha$ and CYP expression (Martínez-Jiménez et al., 2006), though its effects on gene abundance may vary by subfamily (Kim and Novak, 2007).

Understanding the specific mechanisms by which HS reduces reproductive performance is critical for developing strategies to ameliorate its deleterious effects. Altered progesterone metabolism during heat stress could be advantageous for early embryo development, but deleterious for events leading up to fertilization of the oocyte. Until now, indicators of hepatic progesterone metabolism have not been measured in heat-stressed dairy cows. As circulating insulin concentrations increase during HS, hepatic expression of CYP2C and 3A may simultaneously be reduced. Therefore, the objective of these experiments was to determine whether HS with or without insulin treatment affects hepatic mRNA concentrations of progesterone-metabolizing enzymes CYP2C and 3A or their potential regulator, PGC1 $\alpha$.

The data presented are from liver tissues collected during 2 separate experiments that were previously described (Xie et al., 2012, 2013). For both experiments, cows were housed in individual tiestall stanchions in environmental chambers at the University of Arizona Agricultural Research Complex (Tucson) and fed a TMR consisting primarily of alfalfa hay and steamflaked corn. All cows were fed and milked every $12 \mathrm{~h}$. Each trial consisted of 2 experimental periods: (1) 9 d of thermoneutral (TN) conditions with ad libitum intake [TN and well-fed (WF)]; and (2) $9 \mathrm{~d}$ of either HS with ad libitum intake or pair fed in TN conditions $(\mathbf{P F})$. Cows in the TN and WF groups were treated identically during the first period of the experiments (all were WF in TN conditions). During the second period, the group designated $\mathrm{TN}$ were subjected to HS whereas those designated WF were PF. Animals in the PF group were only offered as much TMR as was consumed by those cows in the HS group, thus eliminating confounding effects of dissimilar nutrient intake. In the first experiment, pregnant, multiparous, lactating Holstein cows $(\mathrm{n}=12 ; 305 \pm 33$ DIM; 665 $\pm 18 \mathrm{~kg}$ of $\mathrm{BW}$ ) were randomly assigned to 1 of the 2 environmental treatments. The HS environment included cyclical temperatures $\left[31-40^{\circ} \mathrm{C}, 20 \%\right.$ humidity: minimum temperature-humidity index $(\mathbf{T H I})=73$, maximum THI $=86]$ with the $\mathrm{PF}$ animals remaining in a constant environment of $18^{\circ} \mathrm{C}$. Liver tissue biopsies were performed as previously described (Rhoads et al., 2008) at the end of each period (d 9) and snap-frozen in liquid nitrogen.

In the second experiment, multiparous, lactating Holstein cows $(\mathrm{n}=12 ; 136 \pm 8 \mathrm{DIM} ; 560 \pm 32 \mathrm{~kg}$ of $\mathrm{BW}$ ) were also randomly assigned to 1 of the 2 environmental treatments. These cows had been inseminated before the experiment, but had not been examined for pregnancy. Pregnancy was not confirmed before sample collection because cows would have only been in early pregnancy. At this stage, pregnancy is not expected to affect expression of the genes of interest, and previous experiments in rats indicate that hepatic mRNA concentrations from the CYP genes are not sensitive to changes in the estrous cycle (Lee et al., 2012). The HS environment differed only slightly from the first experiment $\left(31-39^{\circ} \mathrm{C}, 20 \%\right.$ humidity: minimum $\mathrm{THI}=$ 73 , maximum $\mathrm{THI}=80.5$ ), whereas the $\mathrm{PF}$ animals remained in a constant environment of $20^{\circ} \mathrm{C}$. On d 6 of each period, an insulin challenge $(1 \mu \mathrm{g}$ of bovine insulin/kg of BW; Sigma, St. Louis, MO) was administered intravenously. Liver tissue biopsies were collected $15 \mathrm{~min}$ before and $15 \mathrm{~min}$ after the insulin bolus was delivered and snap-frozen in liquid nitrogen.

Liver samples were stored at $-80^{\circ} \mathrm{C}$ until total cellular RNA was extracted (Deaver et al., 2013) and real-time PCR was performed using the SYBR Green PCR Master Mix (Applied Biosystems, Foster City, CA). Primers for the following genes were designed: RPS15 (accession number: NM_001024541; forward: 5'-ATCATTCTACCCGAGATGGT-3'; reverse: 5'-TGCTTCACGGGCTTGTAAGT-3'; annealing temperature: $\left.60.0^{\circ} \mathrm{C}\right)$, cyclophilin $(C Y C$; accession number: AY594336; forward: 5'-GTGGTCATCGGTCTCTTTTGG-3'; reverse: 5'-CACCGTAGATGCTCTTACCTC-3'; annealing temperature: $60.0^{\circ} \mathrm{C}$ ), CYP2C (accession number: NM_001109792; forward: 5'-TATGGACTCCTGCTCCTGCT-3'; reverse: 5'-CATCTGTGTAGGGCATGCAG-3'; annealing temperature: $62.4^{\circ} \mathrm{C}$ ), CYP3A (accession number: BT030557; forward: 5'-GTGCCAATCTCTGT- 
GCTTCA-3'; reverse: 5'-CCAGTTCCAAAAGGCAGGTA-3'; annealing temperature: $62.0^{\circ} \mathrm{C}$ ), and $P G C 1 \alpha$ (accession number: XM_005207759; forward: 5'-CCGAGAATTCATGGAGCAAT-3'; reverse: 5 '-GATTGTGTGTGGGCCTTCTT-3'; annealing temperature: $62.2^{\circ} \mathrm{C}$; Eurofins Genomics, Huntsville, AL). Fold differences were calculated relative to a pooled control sample run on each plate using the PCR efficiency for each individual primer pair. Fold differences were then normalized to the expression of RPS15 (for experiment 1) and $C Y C$ (for experiment 2) as described in Rhoads et al. (2010).

Circulating insulin concentrations were measured in plasma from blood samples collected twice during the control and treatment periods for each experiment $(\mathrm{d}$ 7 and 9 for experiment 1; d 3 and 6 for experiment 2). Insulin was measured using a commercially available ELISA kit (Mercodia Bovine Insulin ELISA; Uppsala, Sweden) with intra- and interassay CV of 7.1 and $6.6 \%$, respectively.

Data for each experiment were analyzed separately using the MIXED procedure in SAS (SAS Institute, Inc., Cary, NC) with treatment as the fixed effect and, when applicable, biopsies from the same animal as the repeated measurements. The compound symmetry, unstructured, and autoregressive 1 covariance structures were tested and the most appropriate (lowest Akaike's information criterion, Akaike's information criterion with correction, and Bayesian information criterion values) was used for each analysis. Results are reported as least squares means \pm standard error of the means. Statistical significance was declared at $P<0.05$ and tendencies were reported at $P<0.15$.

Heat stress induces a unique metabolic state for dairy cattle because even as feed intake decreases, plasma insulin increases. Normally, during inadequate nutrient intake, plasma insulin concentrations decrease and glucose uptake by insulin sensitive tissues is reduced. The physiological rationale for the heat-induced metabolic shift is not well defined, but considered a mechanism to minimize FA oxidation; ostensibly a survival strategy (Wheelock et al., 2010). Previous studies indicate that hepatic metabolism of progesterone is influenced by circulating insulin concentrations (Lemley et al., 2008, 2010; Cooke et al., 2012; Vieira et al., 2013). It is unknown, however, whether this regulatory relationship is maintained during periods of HS.

In our study, insulin was administered only to the cows in mid-lactation. This dose was delivered as a bolus and did not affect the expression of $C Y P 2 C$ or CYP3A (data not shown). Although this would seem to contradict previous reports (Lemley et al., 2008, 2010; Vieira et al., 2013), it is likely due to differences in treatment and sampling protocols. During this experiment, liver biopsies were collected merely 15 min after insulin administration, whereas previous experiments obtained liver biopsies after sustained elevation of circulating insulin concentrations (duration of $3 \mathrm{~h}$ to $35 \mathrm{~d}$ ). Thus, it appears that in the current experiment the interval between insulin administration and sample collection was not sufficient for detecting changes in hepatic $C Y P 2 C$ and $C Y P 3 A$ mRNA. It is important to realize, however, that the lack of effect on mRNA concentrations is not necessarily an indication of actual enzymatic activity. Three hours after feeding an insulin-stimulating diet, Lemley et al. (2010) found that neither circulating insulin concentrations nor hepatic CYP2C and CYP3A mRNA abundance were affected. Nonetheless, $C Y P 2 C$ and $C Y P 3 A$ enzyme activity had decreased. This suggests that changes in post-translational modification of the enzymes may precede changes in mRNA abundance.

In agreement with previous experiments, HS tended to increase circulating insulin concentrations during the second experiment (mid-lactation cows; $P=0.12$;
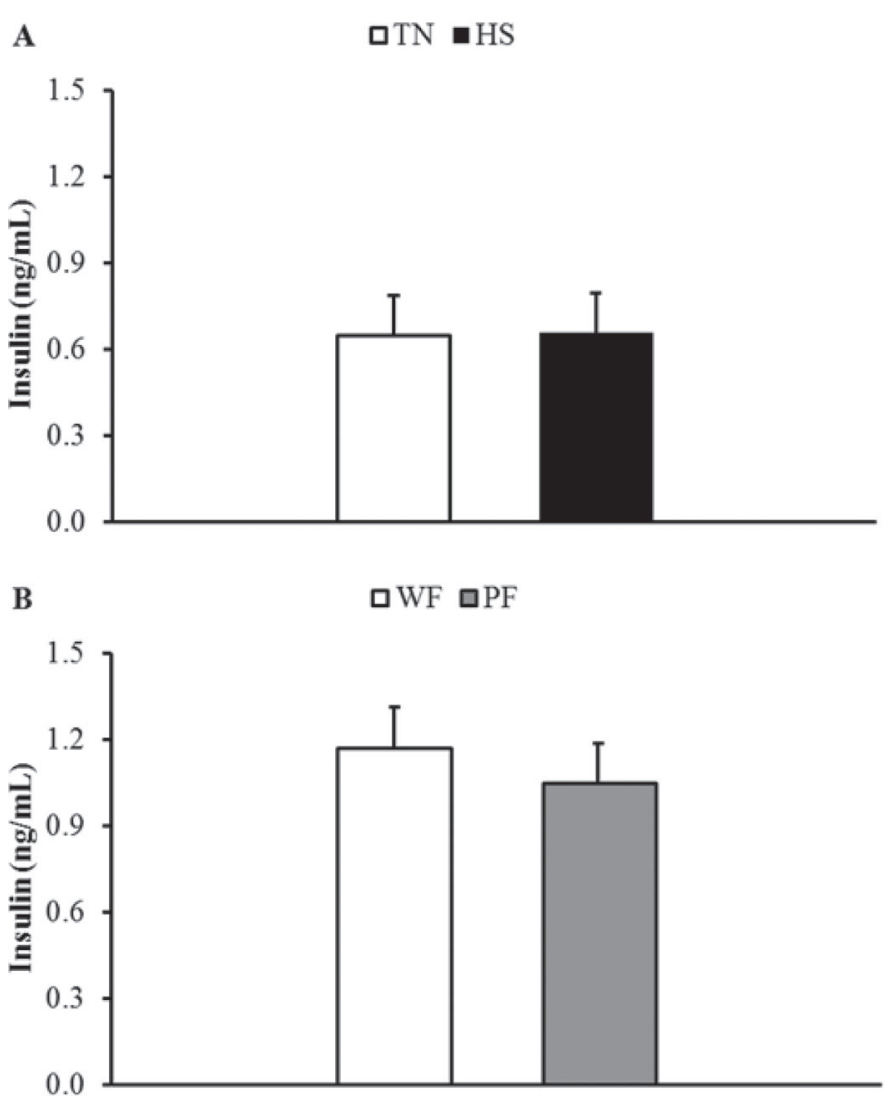

Figure 1. Plasma insulin concentrations of late-lactation cattle (experiment 1) during a thermoneutral (TN) and well-fed (WF) period followed by a period of heat stress (HS; panel A) or pair feeding (PF; panel B). Insulin concentrations were measured in samples collected on $\mathrm{d} 7$ and 9 of each period (TN/WF and HS/PF) and are reported as $\mathrm{LSM} \pm \mathrm{SEM}$. 
$\mathbf{A}$

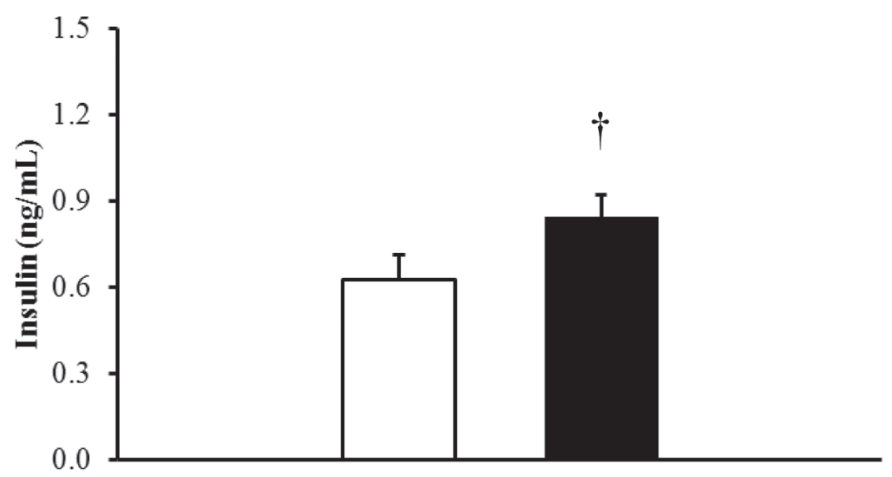

B

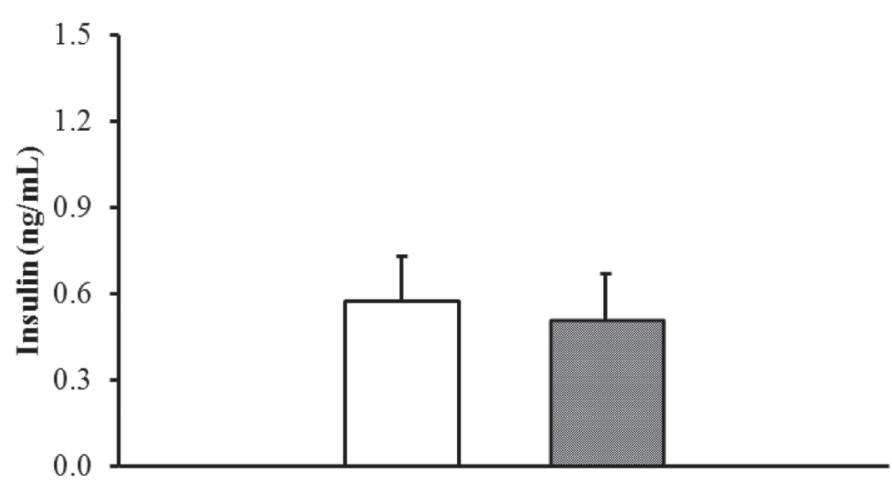

Figure 2. Plasma insulin concentrations of mid-lactation cattle (experiment 2) during a thermoneutral (TN) and well-fed (WF) period followed by a period of heat stress (HS; panel A) or pair feeding (PF; panel B). Insulin concentrations were measured in samples collected on $\mathrm{d} 3$ and 6 of each period (TN/WF and $\mathrm{HS} / \mathrm{PF}$ ) and are reported as $\mathrm{LSM} \pm \mathrm{SEM} ; \dagger P=0.12$

Figure 2). In contrast, HS did not affect plasma insulin concentrations during the first experiment (late-lactation cows; Figure 1). This discrepancy between the 2 experiments is likely related to the cows' relative stages of lactation. In previous work where HS significantly increased circulating insulin concentrations, cattle were $<100$ DIM and produced substantially more milk (Wheelock et al., 2010). Taken together, the results of these experiments suggest early lactation cows are susceptible to HS-induced increases in insulin and that this effect declines over the course of lactation. The period of susceptibility is particularly significant for fertility, as it coincides with the time during which cows are being inseminated and need to become pregnant.

During the first experiment, liver biopsies were collected from late-lactation cows and expression of neither gene was affected by PF (Figure 3). In contrast, during HS, hepatic expression of $C Y P 2 C$ tended to decrease $(P$ $<0.10$ ) and $C Y P 3 A$ remained unchanged (Figure 3). When samples were collected from mid-lactation cows
$\mathbf{A}$

口TN $\square \mathrm{HS}$
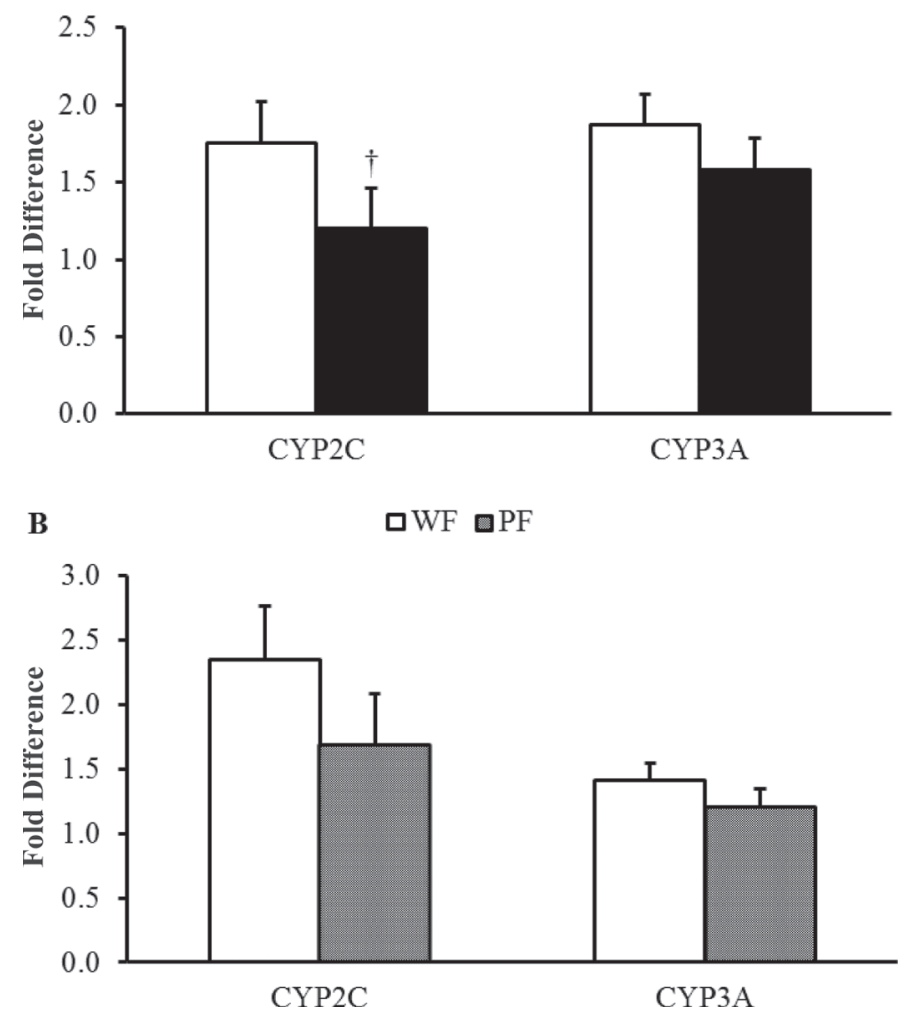

Figure 3. Hepatic mRNA abundance of cytochrome P450 2C $(C Y P 2 C)$ and cytochrome P450 3A (CYP3A) in late-lactation cattle (experiment 1). Gene expression was quantified during a thermoneutral $(\mathrm{TN})$ and well-fed (WF) period followed by a period of heat stress (HS; panel A) or pair feeding (PF; panel B). Values are LSM \pm SEM; $\dagger P \leq 0.10$.

(second experiment), environments affected the expression of $C Y P 2 C$ in a manner similar to the late-lactation cows: there was no change in response to $\mathrm{PF}$ whereas a reduction during HS was noted $(P<0.01$; Figure 4). Unlike late lactation, hepatic abundance of $C Y P 3 A$ decreased during HS of mid-lactation cattle (Figure 4). These results are all consistent with the hypothesis that abundance of these progesterone-metabolizing genes decrease during HS as circulating insulin concentrations increase. Interestingly, CYP3A abundance was also reduced in response to $\mathrm{PF}$ treatments during the second experiment (Figure 4). Evidence from rodent models suggests that undernutrition can indeed reduce hepatic expression of CYP3A (Mao et al., 2006; Ni et al., 2008). To our knowledge, however, this has not been previously investigated in ruminants. The reduction in CYP3A during PF in the second experiment is obviously independent of circulating insulin, suggesting that regulation of this enzyme is multifaceted and may be differentially controlled based upon physiological state. 
$\mathbf{A}$

口TN $\mathbf{H S}$

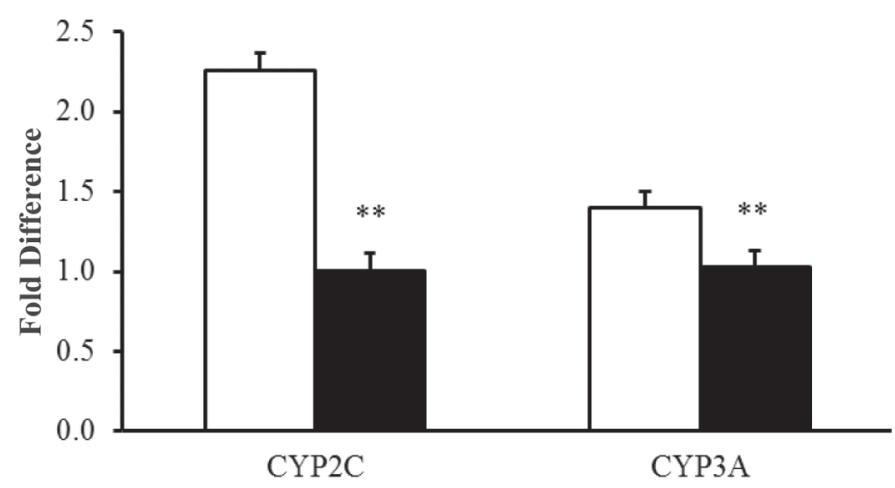

B

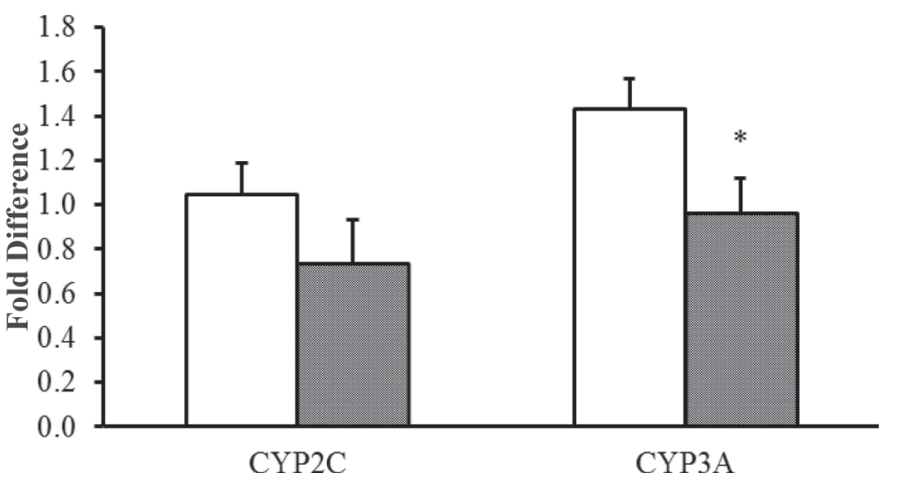

Figure 4. Hepatic mRNA abundance of cytochrome P450 2C (CYP2C) and cytochrome P450 3A (CYP3A) in mid-lactation cattle (experiment 2). Gene expression was quantified during a thermoneutral (TN) and well-fed (WF) period followed by a period of heat stress (HS; panel A) or pair feeding (PF; panel B). Values are LSM \pm SEM; ${ }^{*} P<0.05 ;{ }^{* *} P \leq 0.01$.

Despite environment-induced differences in $C Y P 2 C$ and CYP3A mRNA concentrations, hepatic expression of $P G C 1 \alpha$ did not differ in response to $\mathrm{PF}$ or HS during either experiment ( $P>0.10$; data not shown). This suggests that in these specific experimental conditions, $P G C 1 \alpha$ is not responsible for regulating these progesterone-metabolizing enzymes. It is important to recognize, however, that these experiments were designed to examine gene expression during periods of differing physiological stress. The role of $P G C 1 \alpha$ in cellular function during stress conditions is complex and not yet fully understood (Lindholm et al., 2012). Thus, it remains reasonable to assume that $P G C 1 \alpha$ may regulate the expression of $C Y P 2 C$ or $C Y P 3 A$ during nonstress conditions.

The expression of $C Y P^{2} C$ and $C Y P 3 A$ was differentially regulated by environment during these 2 experiments. Whereas changes in the abundance of $C Y P 2 C$ were similar between the first and second experiments, profiles of CYP3A expression differed between experi- ments. The primary difference between the experiments was the cows' stage of lactation, suggesting that HSinduced regulation of $C Y P 3 A$ changes over the course of lactation, whereas regulation of $C Y P 2 C$ remains constant between mid- and late lactation. Further research is needed to determine how HS-induced changes in $C Y P 2 C$ and $C Y P 3 A$ mRNA abundance affect enzyme activity and, ultimately, progesterone metabolism.

\section{REFERENCES}

Abilay, T. A., H. D. Johnson, and M. Madan. 1975. Influence of environmental heat on peripheral plasma progesterone and cortisol during the bovine estrous cycle. J. Dairy Sci. 58:1836-1840.

Baumgard, L. H., and R. P. Rhoads. 2013. Review: Effects of heat stress on post-absorptive metabolism and energetics. Annu. Rev. Anim. Biosci. 1:311-337.

Cooke, R. F., B. I. Cappellozza, M. M. Reis, D. W. Bohnert, and J. L. Vasconcelos. 2012. Plasma progesterone concentration in beef heifers receiving exogenous glucose, insulin, or bovine somatotropin. J. Anim. Sci. 90:3266-3273.

Deaver, S. E., P. B. Hoyer, S. M. Dial, M. E. Field, R. J. Collier, and M. L. Rhoads. 2013. Localization of ghrelin and its receptor in the reproductive tract of Holstein heifers. J. Dairy Sci. 96:150-157.

Kim, S. K., and R. F. Novak. 2007. The role of intracellular signaling in insulin-mediated regulation of drug metabolizing enzyme gene and protein expression. Pharmacol. Ther. 113:88-120.

Lee, S. Y., S. J. Oh, K. U. Yun, H. M. Kim, B. H. Kim, K. Lee, and S. K. Kim. 2012. Expression of hepatic and ovarian cytochrome P450 during estrous cycle in rats. Arch. Toxicol. 86:75-85.

Lemley, C. O., S. T. Butler, W. R. Butler, and M. E. Wilson. 2008. Short communication: Insulin alters hepatic progesterone catabolic enzymes cytochrome $\mathrm{P} 4502 \mathrm{C}$ and $3 \mathrm{~A}$ in dairy cows. J. Dairy Sci. 91:641-645.

Lemley, C. O., K. A. Vonnahme, L. R. Tager, K. M. Krause, and M. E. Wilson. 2010. Diet-induced alterations in hepatic progesterone (P4) catabolic enzyme activity and $\mathrm{P} 4$ clearance rate in lactating dairy cows. J. Endocrinol. 205:233-241.

Lemley, C. O., and M. E. Wilson. 2010. Effect of cytochrome P450 and aldo-keto reductase inhibitors on progesterone inactivation in primary bovine hepatic cell cultures. J. Dairy Sci. 93:4613-4624.

Lindholm, D., O. Eriksson, J. Makela, N. Belluardo, and L. Korhonen. 2012. PGC-1alpha: A master gene that is hard to master. Cell. Mol. Life Sci. 69:2465-2468.

Mao, Z. L., Y. K. Tam, and R. T. Coutts. 2006. Effect of protein and calorie malnutrition on drug metabolism in rat-In vitro. J. Pharm. Pharm. Sci. 9:60-70.

Martínez-Jiménez, C. P., J. V. Castell, M. J. Gomez-Lechon, and R. Jover. 2006. Transcriptional activation of CYP2C9, CYP1A1, and CYP1A2 by hepatocyte nuclear factor 4alpha requires coactivators peroxisomal proliferator activated receptor-gamma coactivator 1alpha and steroid receptor coactivator 1. Mol. Pharmacol. 70:1681-1692.

Ni, S., X. Wang, J. Wang, S. Lu, S. Zeng, Z. Zhao, L. Yu, and S. Chen. 2008. Effects of intrauterine undernutrition on the expression of CYP3A23/3A1, PXR, CAR and HNF4alpha in neonate rats. Biopharm. Drug Dispos. 29:501-510.

O'Brien, M. D., R. P. Rhoads, S. R. Sanders, G. C. Duff, and L. H. Baumgard. 2010. Metabolic adaptations to heat stress in growing cattle. Domest. Anim. Endocrinol. 38:86-94.

Rhoads, M. L., J. W. Kim, R. J. Collier, B. A. Crooker, Y. R. Boisclair, L. H. Baumgard, and R. P. Rhoads. 2010. Effects of heat stress and nutrition on lactating Holstein cows: II. Aspects of hepatic growth hormone responsiveness. J. Dairy Sci. 93:170-179.

Rhoads, M. L., J. P. Meyer, W. R. Lamberson, D. H. Keisler, and M. C. Lucy. 2008. Uterine and hepatic gene expression in relation to days postpartum, estrus, and pregnancy in postpartum dairy cows. J. Dairy Sci. 91:140-150. 
Rhoads, M. L., R. P. Rhoads, M. J. VanBaale, R. J. Collier, S. R. Sanders, W. J. Weber, B. A. Crooker, and L. H. Baumgard. 2009. Effects of heat stress and plane of nutrition on lactating Holstein cows: I. Production, metabolism, and aspects of circulating somatotropin. J. Dairy Sci. 92:1986-1997.

Roman-Ponce, H., W. W. Thatcher, and C. J. Wilcox. 1981. Hormonal interrelationships and physiological responses of lactating dairy cows to a shade management system in a subtropical environment. Theriogenology 16:139-154.

Rosenberg, M., Y. Folman, Z. Herz, I. Flamenbaum, A. Berman, and M. Kaim. 1982. Effect of climatic conditions on peripheral concentrations of LH, progesterone and oestradiol-17 beta in high milkyielding cows. J. Reprod. Fertil. 66:139-146.

Smith, D. L., B. M. Stinefelt, K. P. Blemings, and M. E. Wilson. 2006. Diet-induced alterations in progesterone clearance appear to be mediated by insulin signaling in hepatocytes. J. Anim. Sci. 84:1102-1109.

Trout, J. P., L. R. McDowell, and P. J. Hansen. 1998. Characteristics of the estrous cycle and antioxidant status of lactating Holstein cows exposed to heat stress. J. Dairy Sci. 81:1244-1250.

Vieira, F. V., R. F. Cooke, A. C. Aboin, P. Lima, and J. L. Vasconcelos. 2013. Short communication: Acute but transient increase in serum insulin reduces messenger RNA expression of hepatic enzymes associated with progesterone catabolism in dairy cows. J. Dairy Sci. 96:1085-1089.

Wheelock, J. B., R. P. Rhoads, M. J. Vanbaale, S. R. Sanders, and L. H. Baumgard. 2010. Effects of heat stress on energetic metabolism in lactating Holstein cows. J. Dairy Sci. 93:644-655.

Wiltbank, M. C., A. H. Souza, P. D. Carvalho, R. W. Bender, and A. B. Nascimento. 2011. Improving fertility to timed artificial insemination by manipulation of circulating progesterone concentrations in lactating dairy cattle. Reprod. Fertil. Dev. 24:238-243.

Wolfenson, D., I. Flamenbaum, and A. Berman. 1988. Hyperthermia and body energy store effects on estrous behavior, conception rate, and corpus luteum function in dairy cows. J. Dairy Sci. 71:3497-3504

Xie, G., L. W. Hall, M. Nearing, L. C. Cole, J. Allen, L. H. Baumgard, D. M. Spurlock, and R. P. Rhoads. 2012. Effects of heat stress and plane of nutrition on adipose tissue metabolism-related gene expression in lactating Holstein cows. J. Dairy Sci. 95(E-Suppl. 2):78-79. (Abstr.)

Xie, G., M. V. Skrzpek, S. R. Sanders, L. H. Baumgard, and R. P. Rhoads. 2013. Effects of heat stress and plane of nutrition on liver insulin responsiveness in lactating cows. J. Dairy Sci. 96(E-Suppl. 1):116. (Abstr.) 